\title{
Obstetric risk indicators for labour dystocia in nulliparous women: A multi-centre cohort study Hanne Kjærgaard*1,3, Jørn Olsen ${ }^{2}$, Bent Ottesen ${ }^{1}$, Per Nyberg ${ }^{3}$ and Anna- Karin Dykes ${ }^{3}$
}

\author{
Address: ${ }^{1}$ Juliane Marie Centre for Women, Children and Reproduction, Copenhagen University Hospital, Rigshospitalet, Denmark, ${ }^{2}$ Department \\ of Epidemiology, School of Public Health, University of California, Los Angeles, USA and ${ }^{3}$ Department of Health Sciences, Faculty of Medicine, \\ Lund University, Sweden \\ Email: Hanne Kjærgaard* - hanne.kjaergaard@rh.regionh.dk; Jørn Olsen - jo@ucla.edu; Bent Ottesen - bent.ottesen@rh.regionh.dk; \\ Per Nyberg - per.nyberg@med.lu.se; Anna-Karin Dykes - anna-karin.dykes@med.lu.se \\ * Corresponding author
}

Published: 6 October 2008

BMC Pregnancy and Childbirth 2008, 8:45 doi:10.1 I86/I47|-2393-8-45

This article is available from: http://www.biomedcentral.com/I47I-2393/8/45

(c) 2008 Kjærgaard et al; licensee BioMed Central Ltd.

This is an Open Access article distributed under the terms of the Creative Commons Attribution License (http://creativecommons.org/licenses/by/2.0), which permits unrestricted use, distribution, and reproduction in any medium, provided the original work is properly cited.
Received: 27 March 2008

Accepted: 6 October 2008

\begin{abstract}
Background: In nulliparous women dystocia is the most common obstetric problem and its etiology is largely unknown. The frequency of augmentation and cesarean delivery related to dystocia is high although it is not clear if a slow progress justifies the interventions. Studies of risk factors for dystocia often do not provide diagnostic criteria for the diagnosis. The aim of the present study was to identify obstetric and clinical risk indicators of dystocia defined by strict and explicit criteria.
\end{abstract}

Methods: A multi-centre population based cohort study with prospectively collected data from 2810 nulliparous women in term spontaneous labour with a singleton infant in cephalic presentation. Data were collected by self-administered questionnaires and clinical data-records. Logistic regression analyses were used to estimate adjusted Odds Ratios (OR) and $95 \%$ confidence intervals $(\mathrm{Cl})$ are given.

Results: The following characteristics, present at admission to hospital, were associated with dystocia during labour (OR, $95 \% \mathrm{Cl}$ ): dilatation of cervix $<4 \mathrm{~cm}(1.63,1.38-1.92)$, tense cervix (I.3I, I.04-I.65), thick lower segment (I.32, I.09-I.6I), fetal head above the inter-spinal diameter $(2.29,1.80-2.92)$ and poor fetal head-to-cervix contact $(1.83,1.3 \mathrm{I}-2.56)$. The use of epidural analgesia $(5.65,4.33-7.38)$ was also associated with dystocia.

Conclusion: Vaginal examinations at admission provide useful information on risk indicators for dystocia. The strongest risk indicator was use of epidural analgesia and if part of that is causal, it is of concern.

\section{Background}

It remains difficult to determine whether a period of slow progress in labour is pathological and therefore justifies treatment, or is a normal variation in the physiological process leading to delivery, especially when the fetal head is above the inter-spinal diameter and the fetal head-tocervix contact is poor. 
Most interventions during nulliparous labour use dystocia as indication and about $50 \%$ of all cesarean deliveries are related to dystocia $[1,2]$. The term dystocia is used by some authors exclusively when immediate instrumental or cesarean delivery is indicated [1], while others, including ourselves, use the term when augmentation is needed regardless of subsequent mode of delivery [3-6]. The incidence of dystocia is not well monitored and there is no consensus on the length of normal labour or the diagnostic criteria for dystocia [1,3,4,7-11]. An increase in the need for augmentation has been reported in affluent countries and some studies show augmentation is now used in around $50 \%$ of nulliparas $[6,12-14]$.

The reasons for the increased incidence of dystocia are only partly known. Poor head-to-cervix force may be associated with slow progress of labour $[15,16]$, as may poor engagement of fetal head at onset of labour [17]. High fetal weight may increase the risk of dystocia [18-20], and it is debated whether epidural analgesia in itself prolongs labour [18,21-27]. With the increasing age in nulliparous women, sub-fecundity is also more frequent and elevated risk of failure to progress was found in fertility-treated pregnancies $[18,28]$. Iatrogenic factors have also been used to explain the increase in dystocia incidence, augmentation and cesarean delivery [29-32]. Most reported associations between dystocia and obstetric risk factors are based on varying criteria for dystocia; often, no criteria are given. We therefore conducted this study, based on strict and explicit criteria, to identify obstetric and clinical risk indicators for dystocia.

\section{Methods}

Data stem from the Danish Dystocia Study, a population based multi-centre study on incidence, risk indicators and women's experiences of labour with dystocia. Participants were part of a fixed cohort of nulliparous women followed from gestational week 37 through 2 weeks after delivery [33]. The final study population comprised 2810 nulliparous women who delivered a singleton infant in cephalic presentation at term after spontaneous onset of labour. The study was restricted to these nulliparas to reduce co-morbidity that could justify induction or a planned cesarean delivery.

Inclusion into the study took place between May 2004 and July 2005. Participants were recruited from four major university hospitals, three county hospitals and two local district departments with annual birth rates varying between 850 and 5400. Recruitment took place in the antenatal clinics at 33 gestational weeks and baseline information was collected at 37 gestational weeks. In order to have a well defined group with no obvious risk factors for dystocia, the following inclusion criteria were used: nulliparas, 18 years of age or older, Danish speak- ing, singleton pregnancy, no planned elective cesarean delivery or induction of labour. From inclusion at gestational week 33 to collection of baseline data in gestational week 37, 202 women were excluded for the following reasons: preterm delivery $(\mathrm{n}=176)$, incorrect inclusion $(\mathrm{n}=$ $8)$, multiple pregnancy $(n=9)$, planned elective cesarean delivery or induction $(n=9)$.

Exclusion criteria at delivery were: $>42+0$ weeks of gestation, induction, elective cesarean delivery and breech presentation (Figure 1). In total 1115 were excluded at delivery. The reasons for exclusion were as follows: induction (including post-term pregnancies) $(\mathrm{n}=741)$, elective caesarean delivery $(n=84)$, breech presentation $(n=178)$ and miscellaneous $(\mathrm{n}=112)$. The latter comprised incorrect inclusion (e.g. non-Danish speaking, $<18$ years at inclusion), foetus mortuus and unspecified. In addition we excluded 138 with no civil registration number, as we would not be able to extract data from the Danish National Birth Register to validate their information. Incomplete sets of data $(\mathrm{n}=560)$ were not included in the analyses and 323 were lost to follow up due to an excessive workload for the midwives $(\mathrm{n}=274)$ and miscellaneous (moved or referred to a hospital outside the participating hospitals, declining further participation and unspecified, $\mathrm{n}=49$ ).

Diagnostic criteria for dystocia are presented in Table 1. These criteria are in accordance with guidelines from Danish Society of Obstetrics and Gynecology [34], supplemented with a criterion for the descending phase of labour's second stage from the guidelines on dystocia from the American College of Obstetrics and Gynecology [1]. To minimize potential misclassification of the dystocia diagnosis in our study, we performed systematic data quality control measures to assess compliance with the protocol criteria. Dystocia was only given as a diagnosis if the duration of labour exceeded the cut-off times of the criteria in Table 1. Women who received augmentation without fulfilling the study criteria for dystocia $(n=299)$ were retained in the population at risk. The dystocia diagnosis was not given to women with absence of contractions after prelabour rupture of membranes (PROM) according to the coding guideline of obstetric interventions in Denmark since treatment of PROM is classified as induction of labour [35].

Exposure data were collected prospectively. Data collection was based on a self-administered questionnaire completed in gestational week 37. Data records were completed by the assisting obstetric staff at the woman's admission to the labour ward, and during and after labour. Local contact persons at the participating centres undertook close supervision during follow-up in all phases of the data collection. 


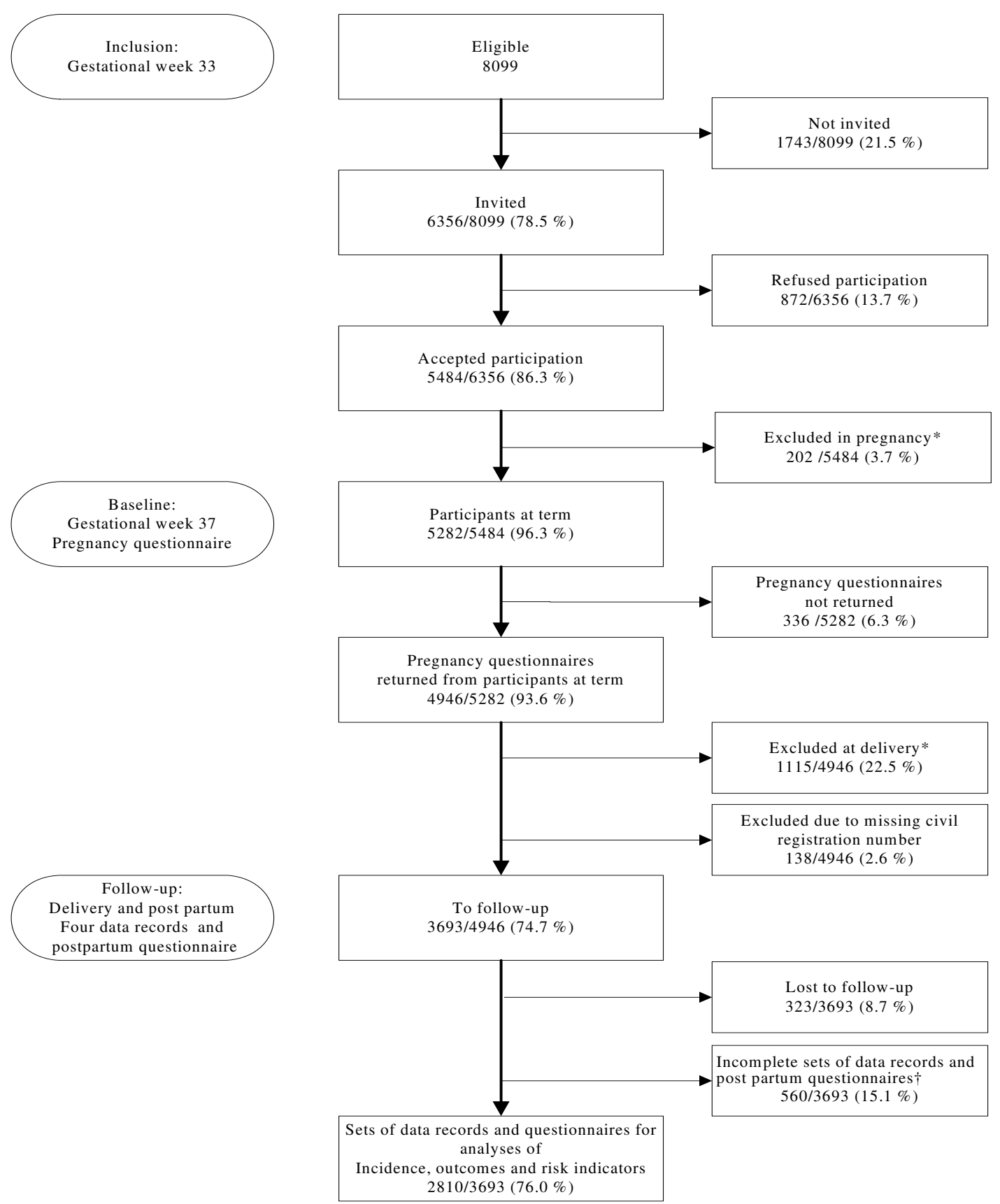

*Exclusion criterea: < 37 or > 42 gestational weeks, multiple pregnancy, breech presentation, elective cesarean delivery, induction and incorrect inclusion into the study

$\dagger$ Incomplete sets of data records and post partum questionnaires usable for analyses in some substudies of The Danish Dystocia Study

\section{Figure I}

\section{The Danish Dystocia Study Flowchart.}


Table I: Definitions of Stages and Phases of Labour and Diagnostic Criteria for Dystocia

\begin{tabular}{|c|c|c|}
\hline Stage of labour & Definition of stage and phase & Diagnostic Criteria for Dystocia \\
\hline First stage & $\begin{array}{l}\text { From onset of regular contractions leading to } \\
\text { cervical dilatation to full dilatation of cervix }\end{array}$ & \\
\hline Latent phase & Cervix $0-3.9 \mathrm{~cm}$ dilatation & The diagnosis was not to be given in this phase \\
\hline Active phase & Cervix $\geq 4 \mathrm{~cm}$ dilatation & $<\mathrm{I} / 2 \mathrm{~cm}$ dilatation of cervix per hour, assessed over 4 hours $=$ dystocia \\
\hline Second stage & From full dilatation of cervix to the child is born & \\
\hline Descending phase & $\begin{array}{l}\text { From full dilatation of cervix to strong } \\
\text { and irresistible urge to push }\end{array}$ & $\begin{array}{l}>2 \text { hours without descent }=\text { dystocia. } \\
\text { If epidural is administered: } \\
>3 \text { hours = dystocia }\end{array}$ \\
\hline Expulsive phase & $\begin{array}{l}\text { Strong and irresistible pushing during the } \\
\text { major part of the contraction }\end{array}$ & $>$ I hour without progress $=$ dystocia \\
\hline
\end{tabular}

The examined risk indicators of dystocia were: dilatation and consistency of cervix, thickness of lower segment, descent of fetal head and fetal head-to-cervix contact at admission to the delivery ward, infertility prior to current pregnancy and use of epidural analgesia. Measurements of lower uterine segment, cervix and fetal head conditions were performed manually during routine vaginal examinations. In the pilot phase of the study two methods of validation of vaginal examinations were considered: use of a model or an additional examination by a second midwife. Both methods were discarded as constituting an unacceptable extra workload and also, in the case of the latter, for ethical reasons. We assumed that the weight of the expected child plays a role in the progress of labour. However, the actual weight of the expected child is unknown and cannot with accuracy be taken into consideration for potential clinical management of the labour. Our analyses included as well as excluded, respectively, birth weight in the regression model to examine the effect of birth weight on the clinical risk indicators.

Prior to analyses, dilatation of cervix and birth weight were categorized according to predefined categories. If epidural analgesia was applied after dystocia was diagnosed and augmentation was initiated $(n=47)$, women were excluded from the risk analyses. The categories of risk indicators are described in Table 2.

\section{Ethics}

Since no invasive procedures were applied in the study, no Ethics Committee System approval was required by Danish law. The policy of the Helsinki Declaration was followed throughout the data collection and analyses. Written consent was obtained and person-specific data were protected by codes. Permission to establish the database was obtained from the Danish Data Protection Agency j. no. 2004-41-3995.

\section{Statistical methods}

Binary logistic regression analyses were used to estimate crude and adjusted odds ratio (OR) for dystocia with 95\% confidence intervals (CI). Adjustments were made for age in four groups $(<25,25-29,30-34,35+)$, height in three groups $(<160,160-169,170+)$, pre-pregnancy BMI in five groups $(<18.5,18.5-24.9,25.0-29.9,30+)$ and level of physical activity in first trimester in four groups (regular intensive physical training and competitive sports several times/week, athletics or heavy physical activity $\geq 4$ hours/ week, light physical activity $\geq 4$ hours/week, predominantly sedentary lifestyle) as these potential confounders may be independent risk factors for dystocia, and some are known to interact with the risk factors under study, i.e. BMI and birth weight and age and infertility. Age, height, pre-pregnancy BMI and level of physical activity were initially all included in the model and subsequently deleted one by one with replacement. None of the variables changed the estimate by more than $10 \%$ but we decided to keep all variables in the model since they did not increase the variance of the OR. We also estimated OR for the clinical risk indicators with all variables included in the model to adjust for their mutual associations and to identify which factors had the strongest independent association. We calculated trend values for continuous variables (cervix dilatation and birth weight) by using logistic regression. Odds ratio for trend represent a change in OR per unit increase or decrease in the exposures under study. In order to take into consideration potential clinical and social characteristics of the nine participating centres, we adjusted all analyses by including study centre in the model as a dummy variable. Descriptive statistics for continuous variables are presented as means with $95 \%$ CI or medians (Inter-quartile range (IQR)) depending on distributional characteristics.

Statistical analyses were performed using SPSS 14.0 software (SPSS Inc., Chicago, Il).

\section{Results}

The mean maternal age was 28.7 years $(95 \% \mathrm{CI} ; 28.5$ 28.8 ) at entry into the cohort, but women with dystocia were slightly older (29.1 yrs.). Median pre-pregnancy BMI was 22.3 (IQR 4.2) with no significant difference between 
Table 2: Odds Ratios for dystocia with $95 \%$ confidence intervals according to obstetric characteristics

\begin{tabular}{|c|c|c|c|c|c|c|}
\hline & N 2810 & $\begin{array}{l}\text { Un-adjusted } \\
\text { OR }\end{array}$ & $\begin{array}{l}\text { Adjusted OR* } \\
(95 \% \mathrm{Cl})\end{array}$ & $\begin{array}{l}\text { All variables } \\
\text { included }\end{array}$ & $\begin{array}{l}\text { All variables included } \\
\text { except birth weight }\end{array}$ & $\begin{array}{l}\text { Trendt OR } \\
(95 \% \mathrm{Cl})\end{array}$ \\
\hline \multicolumn{7}{|l|}{$\begin{array}{l}\text { Infertility treatment prior to current } \\
\text { pregnancy }\end{array}$} \\
\hline No & 2449 & I (ref.) & I (ref.) & I (ref.) & I (ref.) & \\
\hline Yes & 184 & 1.13 & $0.95(0.69-1.31)$ & $0.92(0.65-1.29)$ & $1.09(0.78-1.53)$ & \\
\hline Missing & 177 & & & & & \\
\hline Dilatation of cervix at admission & & & & & & $\begin{array}{c}0.83 \\
(0.80-0.86)\end{array}$ \\
\hline $0-3 \mathrm{~cm}$ & 1086 & 1.67 & $1.63(1.38-1.92)$ & $1.29(1.06-1.57)$ & $1.21(1.00-1.47)$ & \\
\hline $4-10 \mathrm{~cm}$ & 1575 & I (ref.) & I (ref.) & I (ref.) & I (ref.) & \\
\hline Missing & 149 & & & & & \\
\hline \multicolumn{7}{|l|}{ Consistency of cervix at admission } \\
\hline Tense & 585 & 1.25 & $1.31(1.04-1.65)$ & $1.0(0.79-1.26)$ & $0.98(0.79-1.23)$ & \\
\hline Soft & 1794 & I (ref.) & I (ref.) & I (ref.) & I (ref.) & \\
\hline Missing & 431 & & & & & \\
\hline \multicolumn{7}{|c|}{ Thickness of lower segment at admission } \\
\hline Thick & 583 & 1.30 & $1.32(1.09-1.61)$ & $0.88(0.69-1.12)$ & $0.91(0.72-1.14)$ & \\
\hline Thin & 1712 & I (ref.) & I (ref.) & I (ref.) & I (ref.) & \\
\hline Missing & 515 & & & & & \\
\hline \multicolumn{7}{|l|}{ Descent of fetal head at admission } \\
\hline Above the inter-spinal-line & 2367 & 2.33 & $2.29(1.80-2.92)$ & $1.80(1.32-2.45)$ & $1.92(1.42-2.58)$ & \\
\hline At or under the inter-spinal-line & 311 & I (ref.) & i (ref.) & I (ref.) & I (ref.) & \\
\hline Missing & 132 & & & & & \\
\hline \multicolumn{7}{|l|}{ Fetal head-to-cervix contact } \\
\hline Good & 1921 & I (ref.) & I (ref.) & I (ref.) & I (ref.) & \\
\hline Poor & 159 & 1.88 & $1.83(1.31-2.56)$ & $1.62(1.09-2.40)$ & $1.57(1.08-2.27)$ & \\
\hline Cannot be assessed & 455 & & & & & \\
\hline Missing & 275 & & & & & \\
\hline Birth weight & & & & & & $\begin{array}{c}1.001 \\
(1.00-1.00)\end{array}$ \\
\hline $2000-2499 \mathrm{gr}$ & 23 & 0.14 & $0.14(0.32-0.60)$ & $0.27(0.6 \mathrm{I}-\mathrm{I} .2 \mathrm{I})$ & & \\
\hline $2500-2999 \mathrm{gr}$ & 282 & 0.57 & $0.51(0.38-0.69)$ & $0.55(0.40-0.77)$ & & \\
\hline $3000-3499 \mathrm{gr}$ & 1040 & 0.78 & $0.74(0.62-0.89)$ & $0.76(0.62-0.93)$ & & \\
\hline $3500-3999 \mathrm{gr}$ & 1016 & I (ref.) & I (ref.) & I (ref.) & & \\
\hline $4000-4499 \mathrm{gr}$ & 392 & 1.23 & $1.29(1.02-1.65)$ & $1.06(0.83-\mid .4 I)$ & & \\
\hline$\geq 4500 \mathrm{gr}$ & 53 & 1.36 & $1.37(0.78-2.41)$ & $1.32(0.70-2.46)$ & & \\
\hline \multicolumn{7}{|l|}{ Epidural analgesia } \\
\hline No epidural & 2284 & I (ref.) & I (ref.) & I (ref.) & I (ref.) & \\
\hline Epidural analgesia & 316 & 5.49 & $5.65(4.33-7.38)$ & $4.65(3.53-6.13)$ & $4.77(3.65-6.22)$ & \\
\hline
\end{tabular}

* Crude Odds Ratios controlled for age, height, pre-pregnancy BMI and physical activity, including a variable for the participating departments $(9$ levels).

† Test for trend performed on continuous variables. First line: Regression coefficient for change in OR per unit increased, second line: $95 \% \mathrm{Cl}$.

the two groups. In this population $84 \%$ were non-smokers and 66\% were engaged in light physical activity $>4$ hours per week.

Table 2 presents the unadjusted and adjusted OR within categories of obstetric risk indicators. Among the risk indicators recorded at the woman's admission to the delivery ward, cervix dilatation $<4 \mathrm{~cm}$, descent of fetal head above the inter-spinal level and poor fetal head-to-cervix contact had the strongest association with dystocia.

Epidural analgesia was also strongly associated with dystocia. The variables related to cervix are closely correlated (part of the same manifestation) and when we included all variables from Table 2 in the statistical model, most estimates were attenuated as expected. After mutual adjustments the estimates that remained strongest were epidural analgesia, descent of fetal head above the interspinal diameter, poor fetal head-to-cervix contact and dilatation of cervix $<4 \mathrm{~cm}$ at admission.

Expecting a child with a birth weight $<3500$ gr. appeared to be protective for dystocia while expecting a child with a birth weight $>4000$ gr. was associated with increased risk of dystocia compared to birth weights 3500-3999 gr. The last column presents OR without birth weight included in 
the statistical model. Birth weight appeared to have a minor effect on OR and confidence intervals of the clinical risk indicators.

\section{Discussion}

The vaginal examinations at the woman's admission to the labour ward provided several prognostic indicators of dystocia later in labour. Expecting a child with a high birth weight and the use of epidural analgesia were also associated with the risk of dystocia, the latter association being particularly strong.

Fetal head above the inter-spinal diameter had the strongest association with dystocia among the factors present at admission of women in labour, also in the analyses that excluded birth weight. Others have found that lack of descent of fetal head often leads to cesarean delivery for dystocia $[17,36]$. Descent of fetal head is correlated to dilatation of the cervix, and cervix dilatation $<4 \mathrm{~cm}$ at admission was associated with an increased risk of dystocia. Women admitted with little cervical dilatation may have unbearably painful contractions. Anxiety may play a role for early admission as well as concern for high maternal blood pressure, fetal heart rates or other clinical conditions. High risk of dystocia in women admitted in early labour has also been found other studies [29,30,37,38], perhaps because early admission introduces risk of iatrogene-induced treatments $[29,30]$. We believe, however, that quality control of our data prior to analyses ensured that the dystocia diagnosis was registered exclusively in women who met the criteria. We therefore assume that iatrogenic factors have not played a major role in our findings.

A poor fetal head-to-cervix contact at admission was associated with near doubling of the odds of dystocia. Gough et al. found that low head-to-cervix force was associated with poor progress and delivery by cesarean section for dystocia [39]. Allman et al. examined the head-to-cervix force electronically and advocate that head-to-cervix force is a better predictor of the likely rate of cervical dilatation than intrauterine pressure and also a better predictor of mode of delivery than the dilatation rate itself $[15,16]$. Our findings based on manual assessments during vaginal examinations support Allman's findings of an association between poor head-to-cervix contact and dystocia.

Epidural analgesia had the strongest association with dystocia among the risk indicators assessed. In total $71.2 \%$ of women who were treated with epidural analgesia were diagnosed with dystocia. A similarly strong association between dystocia and epidural analgesia was reported from a population-based study of 106,755 deliveries without induction and with durations of delivery $<12$ hours [14], but the literature is inconsistent on the effects of epidural analgesia on the course of labour and delivery and maternal and fetal outcomes [18,21-27]. Lower plasma oxytocin levels are found in women with epidural analgesia [40] and this may slow the progress of labour. Alehagen et al. found that women who received epidural analgesia had experienced more fear, but not more pain, before the administration of epidural analgesia than did women who did not receive epidural analgesia [41] and fear may prolong duration of labour [42]. Recent reviews come to the conclusion that epidural analgesia appears to prolong labour's second stage and prompt more use of oxytocin [25-27]. Although we excluded from the analyses those who were treated with epidural analgesia after being diagnosed with dystocia, reverse causation is still a possible explanation of the association we find. If a need for pain relief or fear of pain are among the clinical precursors of dystocia, epidural analgesia could be part of the mechanism leading to dystocia.

We were not able to replicate findings of an association between dystocia and infertility treatment prior to the current pregnancy, perhaps because our statistical power to detect such an association is low. Others have demonstrated a near doubling of the risk of failure to progress in treated women [18].

Our findings of an association between high birth weight (4000-4499 gr.) and dystocia corroborate findings from other studies even though the definition of 'high birth weight' varies $[19,20,22]$. Although the birth weight can only be estimated before the child is born, the clinical implication of our findings could be that increased risk of dystocia should be considered when an estimated birth weight is more than 4000 gr.

Our findings of association between the clinical conditions dilatation of cervix, descent of fetal head and fetal head-to-cervix contact and dystocia may have significant clinical implications. Women admitted to hospital for delivery have a vaginal examination upon admittance and information from this examination provides the clinical basis for the primary management of labour. Weight of the child appears to have only minor effect on the OR related to the clinical conditions.

\section{Strengths and limitations}

The study has limitations. We reached $78.5 \%$ of the women eligible for inclusion in the study and of these $86.3 \%$ accepted the invitation to participate. Missed inclusions were mainly a problem during the first months of data collection and we have no reason to believe that this led to over-sampling of women with low or high risk of dystocia as inclusion took place 6-8 weeks before delivery. Almost nine percent were lost to follow up, possibly related to the extra work required from the participating 
departments. The aims of the Danish Dystocia Study were descriptive as well as analytical and the data collection instruments comprised four detailed data records to be filled in by the obstetric staff during the woman's stay at the delivery ward. It may be that the mere burden of work gave rise to some non-responses to items or non-completion of entire data records. However, we have no reason to assume that non-responses were directly related to risk of dystocia.

We did not include an independent criterion for dystocia based on descent of the fetal head and cases with a quick descent but a slow dilatation may have been classified as dystocia. We recommend that future studies make it possible to identify this group. Evaluation of cervical conditions and descent of fetal head is difficult and subject to considerable intra- and inter observer variation. We recommend that further studies include different methods of measuring conditions related to the cervix and the fetal head (i.e. electronic monitoring).

The study also has important strengths. The population based cohort design, based upon primary and prospectively collected data, is a strength. The risk of differential misclassification was reduced as we used prospectively collected data on cervix and fetal head conditions and the study was based on strict diagnostic criteria agreed upon by all. Central as well as local supervisors took part in all phases of the data collection.

\section{Conclusion}

Our study contributes further evidence of an increased risk of dystocia in nulliparous women who, at admission to hospital, present with a descent of fetal head above the inter-spinal diameter and a cervix dilatation $<4 \mathrm{~cm}$. We found that a tense cervix, a thick lower segment and a poor contact between the fetal head and the cervix are risk indicators for dystocia. Further studies should examine if fetal head-to-cervix contact is a significant predictor of dystocia and if differentiation of the management of dystocia can be based on assessment of fetal head-to-cervix contact. The observed association between epidural analgesia and increased risk of dystocia is of interest and may have a causal explanation.

\section{Competing interests}

The authors declare that they have no competing interests.

\section{Authors' contributions}

HK and AKD planned the study. HK carried out the data collection. Analyses were planned by HK, JO and PN. PN conducted the data validation. HK conducted the analyses. $\mathrm{HK}, \mathrm{BO}, \mathrm{AKD}$ and JO interpreted the results. HK wrote the drafts of the manuscript, which the other authors commented on. All authors approved the final manuscript.

\section{Acknowledgements}

Christina Vestergaard is thanked for assistance in processing data and Steen Rasmussen for data extraction from the Danish Medical Birth Register.

\section{References}

I. American College of Obstetrics and Gynecology. ACOG Practice Bulletin Number 49, December 2003: Dystocia and augmentation of labor. Obstet Gynecol 2003, I 02: I 445- I 454.

2. Gifford DS, Morton SC, Fiske M, Keesey J, Keeler E, Kahn KL: Lack of progress in labor as a reason for cesarean. Obstet Gynecol 2000, 95:589-595.

3. Foley ME, Alarab M, Daly L, Keane D, Rath A, O'Herlihy C: The continuing effectiveness of active management of first labor, despite a doubling in overall nulliparous cesarean delivery. Am J Obstet Gynecol 2004, 191:891-895.

4. Sosa CG, Balaguer E, Alonso JG, Panizza R, Laborde A, Berrondo C: Meperidine for dystocia during the first stage of labor. A randomized controlled trial. Am J Obstet Gynecol 2004, 191:|2|2-1218.

5. Cluett ER, Pickering RM, Getliffe K, St George Saunders NJ: Randomised controlled trial of labouring in water compared with standard of augmentation for management of dystocia in first stage of labour. BMJ 328(7435):314. 2004 Feb 7; Epub 2004 Jan 26

6. Treacy A, Robson M, O'Herlihy C: Dystocia increases with advancing maternal age. Am J Obstet Gynecol 2006, 195:760-763.

7. Friedman E: Labor, clinical evaluation and management 2nd edition. New York: Appleton-Century-Crofts; 1978.

8. Vahratian A, Troendle JF, Siega-Riz AM, Zhang J: Methodological challenges in studying labour progression in contemporary practice. Paediatr Perinat Epidemiol 2006, 20:72-78.

9. Greenberg MB, Cheng YW, Hopkins LM, Stotland NE, Bryant AS, Caughey $A B$ : Are there ethnic differences in the length of labor? Am J Obstet Gynecol 2006, 195:743-748.

10. Zhu BP, Grigorescu V, Le T, Lin M, Copeland G, Barone M: Labor dystocia and its association with interpregnancy interval. Am J Obstet Gynecol 2006, I 95: 12 I- 28.

II. Turcot L, Marcoux S, Fraser WD: Multivariate analysis of risk factors for operative delivery in nulliparous women. Canadian Early Amniotomy Study Group. Am J Obstet Gynecol I997, I 76:395-402.

12. Danish Medical Birth Register [http://www.sst.dk]

13. Blix E, Pettersen SH, Eriksen H, Royset B, Pedersen EH, Oian P: [Use of oxytocin augmentation after spontaneous onset of labor]. Tidsskr Nor Laegeforen 2002, I 22:1359-1362.

14. Oscarsson ME, Ahmer-Wåhlin I, Rydhstroem H, Kallen K: Outcome in obstetric care related to oxytocin use. A population-based study. Acta Obstet Gynecol Scand 2006, 85: 1094-1098.

15. Allman AC, Genevier ES, Johnson MR, Steer PJ: Head-to-cervix force: an important physiological variable in labour. 2. Peak active force, peak active pressure and mode of delivery. $\mathrm{Br}$ Obstet Gynaecol 1996, 103:769-775.

16. Allman AC, Genevier ES, Johnson MR, Steer PJ: Head-to-cervix force: an important physiological variable in labour. I. The temporal relation between head-to-cervix force and intrauterine pressure during labour. $\mathrm{Br} J$ Obstet Gynaecol 1996, 1 03:763-768.

17. Roshanfekr D, Blakemore KJ, Lee J, Hueppchen NA, Witter FR: Station at onset of active labor in nulliparous patients and risk of cesarean delivery. Obstet Gynecol 1999, 93:329-33I.

18. Sheiner E, Levy A, Feinstein U, Hallak M, Mazor M: Risk factors and outcome of failure to progress during the first stage of labor: a population-based study. Acta Obstet Gynecol Scand 2002, 81:222-226

19. Sheiner E, Levy A, Feinstein U, Hershkovitz R, Hallak M, Mazor M: Obstetric risk factors for failure to progress in the first versus the second stage of labor. J Matern Fetal Neonatal Med 2002, I I:409-4I3.

20. Mocanu EV, Greene RA, Byrne BM, Turner MJ: Obstetric and neonatal outcome of babies weighing more than $4.5 \mathrm{~kg}$ : an analysis by parity. Eur J Obstet Gynecol Reprod Biol 2000, 92:229-233. 
21. Feinstein U, Sheiner E, Levy A, Hallak M, Mazor M: Risk factors for arrest of descent during the second stage of labor. Int J Gynaecol Obstet 2002, 77:7-14.

22. Schiessl B, Janni W, Jundt K, Rammel G, Peschers U, Kainer F: Obstetrical parameters influencing the duration of the second stage of labor. Eur J Obstet Gynecol Reprod Biol 2005, I I 8: 17-20.

23. Fraser WD, Cayer M, Soeder BM, Turcot L, Marcoux S: Risk factors for difficult delivery in nulliparas with epidural analgesia in second stage of labor. Obstet Gynecol 2002, 99:409-4I 8.

24. Zhang J, Yancey MK, Klebanoff MA, Schwarz J, Schweitzer D: Does epidural analgesia prolong labor and increase risk of cesarean delivery? A natural experiment. Am J Obstet Gynecol 200I, 185:128-134.

25. Anim-Somuah M, Smyth R, Howell C: Epidural versus non-epidural or no analgesia in labour. Cochrane Database Syst Rev 2005:CD000331.

26. Leighton $\mathrm{BL}$, Halpern $\mathrm{SH}$ : The effects of epidural analgesia on labor, maternal, and neonatal outcomes: a systematic review. Am J Obstet Gynecol 2002, I86:S69-S77.

27. Lieberman $E, O^{\prime}$ donoghue $C$ : Unintended effects of epidural analgesia during labor: a systematic review. Am J Obstet Gynecol 2002, I86:S3I-S68.

28. Tanbo T, Dale PO, Lunde O, Moe N, Abyholm T: Obstetric outcome in singleton pregnancies after assisted reproduction. Obstet Gynecol 1995, 86: I88-192.

29. Bailit JL, Dierker L, Blanchard MH, Mercer BM: Outcomes of women presenting in active versus latent phase of spontaneous labor. Obstet Gynecol 2005, I 05:77-79.

30. Rahnama $P$, Ziaei S, Faghihzadeh S: Impact of early admission in labor on method of delivery. Int J Gynaecol Obstet 2006, 92:217-220

31. Johanson R, Newburn M, Macfarlane A: Has the medicalisation of childbirth gone too far? BM] 2002, 324:892-895.

32. Bell JS, Campbell DM, Graham WJ, Penney GC, Ryan M, Hall MH: Can obstetric complications explain the high levels of obstetric interventions and maternity service use among older women? A retrospective analysis of routinely collected data. BJOG 200I, 108:910-918.

33. Kiærgaard H: Dystocia in nulliparous women. Incidence, outcomes, risk indicators and women's experiences. In PhD thesis Lund University, Department of Health Sciences, Faculty of medicine, Sweden; 2007.

34. Danish Society of Obstetrics and Gynecology [http:// www.dsog.dk]

35. Coding guidelines of obstetric interventions in Denmark [http://www.dsog.dk/files/Obstetriske koder 101/2005.pdf]

36. Falzone S, Chauhan SP, Mobley JA, Berg TG, Sherline DM, Devoe LD: Unengaged vertex in nulliparous women in active labor. A risk factor for cesarean delivery. I Reprod Med 1998, 43:676-680.

37. Holmes P, Oppenheimer LW, Wen SW: The relationship between cervical dilatation at initial presentation in labour and subsequent intervention. BJOG 200I, 108: I I20-I I 24.

38. McNiven PS, Williams JI, Hodnett E, Kaufman K, Hannah ME: An early labor assessment program: a randomized, controlled trial. Birth 1998, 25:5-10.

39. Gough GW, Randall NJ, Genevier ES, Sutherland IA, Steer PJ: Headto-cervix forces and their relationship to the outcome of labor. Obstet Gynecol 1990, 75:6|3-618.

40. Rahm VA, Hallgren A, Hogberg H, Hurtig I, Odlind V: Plasma oxytocin levels in women during labor with or without epidural analgesia: a prospective study. Acta Obstet Gynecol Scand 2002, 81:1033-1039.

4I. Alehagen S, Wijma B, Lundberg U, Wijma K: Fear, pain and stress hormones during childbirth. Journal of Psychosomatic Obstetrics and Gynecology 2005, 26: 153-165.

42. Lederman RP, Lederman E: The relationship of maternal anxiety, plasma catecholamines and plasma cortisol to progress in labor. Am J Obstet Gynecol 1978, I 32:495-500.

\section{Pre-publication history}

The pre-publication history for this paper can be accessed here: http://www.biomedcentral.com/1471-2393/8/45/prepub
Publish with Biomed Central and every scientist can read your work free of charge

"BioMed Central will be the most significant development for disseminating the results of biomedical research in our lifetime. "

Sir Paul Nurse, Cancer Research UK

Your research papers will be:

- available free of charge to the entire biomedical community

- peer reviewed and published immediately upon acceptance

- cited in PubMed and archived on PubMed Central

- yours - you keep the copyright
BioMedcentral 